\title{
Intermittent maple syrup urine disease
}

INSERM

\section{Source}

INSERM. (1999). Orphanet: an online rare disease and orphan drug data base.

Intermittent maple syrup urine disease. ORPHA:268173

Intermittent maple syrup urine disease (intermittent MSUD) is a mild form of MSUD (see this term) where patients (when well) are asymptomatic with normal levels of branchedchain amino acids (BCAAs) but with catabolic stress are at risk of acute decompensation with ketoacidosis, which can lead to cerebral edema and coma if untreated. 